\title{
El XXX Congreso Mundial de Urbanismo Y Turismo
}

$71: 061.3$

$380.8: 061.3$

\author{
por \\ JUAN AGUILO AGUILO \\ Secretario del Ayuntamiento de San Adrián de Besós
}

Del 17 al 23 de mayo próximo pasado ha tenido lugar en Barcelona (Palacio de las Naciones) el XXX Congreso Mundial de Urbanismo y Turismo, organizado por la Federación Internacional de Vivienda y Urbanismo y con el éxito por todos conocido.

Dicha Federación no estatal es la más importante en el campo de la Vivienda y el Urbanismo. Fundada en 1913, su sede está en La Haya, 43 Wasenaarseweg, organiza sus Congresos cada dos años, contando con la colaboración de los principales expertos europeos. Suelen tratarse temas importantes, a base de ponencias sobre pla. neamiento físico, social y económico, redistribución de la población, nuevas ciudades, áreas rurales, niveles de vivienda, tráfico, etc. Dicho organismo observa una neutralidad estricta en cuestiones políticas, religiosas y raciales.

Nuestro Ministro de la Vivienda en el acto de la inauguración destacó el progreso tecnológico del mundo, acortador de distancias, detallando la hora de universalización actual y las necesidades del hombre y su significación, así como la conexión de los términos «Urbanismo» $y$ «Turismo» y la utilización racional de zonas turísticas y mejora del medio ambiente.

El Presidente de la «F. I. U. A. T. V.», Bure, explicó que a su juicio la palabra francesa de urbanismo debiera ser sustituida por la de planeamiento del territorio, como se ha hecho en Inglaterra con el planning y en Alemania con el Planuog, según ya se ha hecho con la Unión Internacional de Ciudades y Poderes Locales y la Sociedad America- 
na de Urbanismo CIAP en 1969. Aludió a las propagandas de las inmobiliarias para «casas de vacaciones», con olvido de la necesaria infraestructura, haciendo especial mención de la Costa Brava, para concretar que ningún pais del mundo puede prescindir de preocupaciones urbanísticas, dada la universalización del fenómeno, explicando lo que ha de entenderse por financiación del alojamiento, a sus métodos, a la presión y a la opinión pública, abogando por el pla. neamiento regional, con expresión de sus ventajas.

La primera ponencia corrió a cargo del Arquitecto del Ministerio de Información y Turismo don Luis Casanova Vila, quien habló del turismo y su importancia en los países en vía de desarrollo, señalando la de los recursos turisticos naturales de las ciudades de vacaciones y de los atractivos de un pais climatológicamente apto. Comentó el aumento de la población mundial, de las áreas metropolitanas y citó a Tokio como la mayor del mundo en densidad, con los 11.000 .000 de habitantes.

En las cuestiones sujetas a estudio habló de las normas, criterios y casos concretos, haciéndose especial mención de la Carta de Atenas, refiriéndose a los grupos que a partir de 1963 se reúnen en Delgos anualmente para tratar de Ekistica, o ciencia de asentamientos humanos, condicionada por el hombre e influida por las ciencias económicas, sociales, administrativas y técnicas e incluso por el arte. Terminó su lección con el estudio de los problemas de la contaminación atmosférica, agua de los rios, flora y fauna del mar y residuos petrolíferos, temas todos ellos tratados en Strasbourg muy recientemente en la Primera Conferencia europea sobre conservación de la Naturaleza.

La segunda ponencia, sobre métodos de financiación de vivienda, fue detallada por M. Ake Jhonson, destacando la intervención del miembro español del Consejo, don Mario Gómez Morán, sobre palpitantes cuestiones que resumimos así:

a) Financiación del «habitat social», describiendo la política española sobre viviendas antes y después del II Plan de Desarrollo.

b) Las subvenciones a fondo perdido, los préstamos hipotecarios con o sin intereses $y$ bonificaciones fiscales $y$

c) Destrucciones de zonas insalubres y lucha contra el chabolismo en las zonas suburbiales.

En relación con la financiación de la vivienda social se expusieron constructivas ideas sobre las etapas adecuadas para una acertada in- 
dustrialización de la construcción: normalización, coordinación dimensional, realización y prefabricación.

Con referencia a España, se destacó la conveniencia de no adoptar procedimientos eliminatorios de la mano de obra, que exijan alto nivel industrial y servicios innecesarios por la dulzura del clima en muchas regiones. Asimismo sê habló de la falta de concentración empresarial en nuestro país y a los fracasos observados en ensayos debidos a la falta de calidad de áridos, empleo desacertado de piezas desmontables o paneles, y por último el señor Gómez Morán aconsejó una gran prudencia para evitación de inversiones extraordinarias, terminando con la afirmación de que aún no se entiende llegada la gran hora soñada de la gran industrialización, con la afirmación de que, poco a poco, se irá avanzando hasta conseguir grados superiores. 
